\title{
Theoretical Evaluation of the Corrosion Inhibition Performance of an Organic Heterocyclic Compound
}

\author{
Zineb TRIBAK ${ }^{1, *}$, Mohammed Khalid SKALLI ${ }^{1}$ and Omar SENHAJI ${ }^{2}$ \\ ${ }^{1}$ Laboratory of Applied Organic Chemistry, Faculty of Sciences and Technology, \\ Sidi Mohamed Ben Abdellah University, Fez, Morocco \\ ${ }^{2}$ Biomolecular and Macromolecular Chemistry Team, Faculty of Sciences, Moulay Ismail University, \\ Meknes, Morocco
}

('Corresponding author's e-mail: tribak.zineb@gmail.com)

Received: 6 November 2019, Revised: 11 March 2020, Accepted: 5 April 2020

\begin{abstract}
The corrosion inhibition performance of a corrosion inhibitor on mild steel in phosphoric acid, namely 5-chloro-1-(2-(dimethylamino) ethyl) indoline-2,3-dione $\left(\mathbf{T Z}_{\mathbf{C D I}}\right)$, was theoretically evaluated using density functional theory (DFT) at the B3LYP/6-31G+(d,p) level for all atoms by Gaussian 09W program. The quantum chemical properties, such as highest occupied molecular orbital energy $\left(E_{\text {НОмо }}\right)$, lowest unoccupied molecular orbital energy $\left(E_{L U M O}\right)$ energy gap $\left(\Delta E_{\text {gap }}\right)$, dipole moment $(\mu)$, total hardness $(\eta)$, and electronegativity $(\chi)$, were studied, and these descriptors were discussed in connection to the experimental inhibitory efficiency. The local reactivity was analyzed through the Fukui function in order to compare the possible sites for nucleophilic and electrophilic attacks. Accordingly, all data obtained using various theoretical calculation techniques were consistent with experiments.
\end{abstract}

Keywords: 5-Chloroisatin derivative, Corrosion inhibitor, DFT, Fukui function, Experiment, Theoretical studies

\section{Introduction}

The corrosion of mild steel in acidic media is an electrochemical process that returns a metal to its natural state; it is one of the major challenges in industries, as the production, transportation, storage, and refinery operations needed cause losses of millions of dollars annually, along with other safety and economic problems [1,2].

The most practical and popular methods of corrosion protection use the inhibitors; especially organic ones, which are heterocyclic compounds, containing nitrogen, oxygen, and sulfur atoms, either in aromatic or long chain carbon systems, also, the availability of $\pi$-electrons, and suitable functional groups, could be efficient corrosion inhibitors on mild steel surfaces in acidic medium [3].

Recently, previous studies in the corrosion field showed that the indole and their several derivatives are reported as useful corrosion inhibitors for diverse metals and alloys in various media [4]. Tribak et al. [5] reported that $\mathbf{T Z}$ CDI possesses anticorrosion properties due to the presence of nitrogen and oxygen atoms, as well as other functional groups. The isatin derivatives also provide analgesic [6] antiinflammatory [7] antitumor [8] antibacterial [9-11] and relaxant effects [12] and therapeutic agents [13].

Quantum chemical methods using the density function theory (DFT) approach are widely employed for the study of the physico-chemical interactions between organic corrosion inhibitors and metal substrates, and also the estimation of other quantum chemical parameters [14]. 
Herein, we have synthesized $\mathbf{T} \mathbf{Z}_{\mathbf{C D I}}$ and studied its properties as a corrosion inhibitor for mild steel in $1 \mathrm{M} \mathrm{H}_{3} \mathrm{PO}_{4}$ medium using experimental techniques and theoretical calculation through the DFT (DFT/B3LYP/6-31G+(d,p)) method $[15,16]$.

\section{Materials and methods}

Metal

The mild steel sheet $\left(1.5 \times 1.5 \mathrm{~cm}^{2}\right)$ used in the study had the following chemical composition: 0.370 $\%$ C, $0.230 \% \mathrm{Mn}, 0.680 \% \mathrm{Si}, 0.016 \% \mathrm{~S}, 0.077 \% \mathrm{Cr}, 0.011 \% \mathrm{Ti}, 0.059 \% \mathrm{Ni}, 0.009 \%$ Co, and 0.160 $\% \mathrm{Cu}$, with the balance being iron $(\mathrm{Fe})$. The metal was degreased by washing with acetone.

\section{Solution}

The blank acid solution $\left(1 \mathrm{M} \mathrm{H}_{3} \mathrm{PO}_{4}\right)$ was prepared by diluting analytical grade phosphoric acid 85 $\%$ with double distilled water. Various concentrations $\left(10^{-6}\right.$ to $\left.10^{-3} \mathrm{M}\right)$ of the synthesized $\mathbf{T Z}$ CDI were also prepared and used as inhibitors for mild steel corrosion in $1 \mathrm{M} \mathrm{H}_{3} \mathrm{PO}_{4}$.

\section{Synthesis of studied inhibitor}

5-Chloroisatin $(0.2 \mathrm{~g}, 1.1 \mathrm{mmol})$, potassium carbonate $\mathrm{K}_{2} \mathrm{CO}_{3}(0.23 \mathrm{~g}, 1.16 \mathrm{mmol})$, and Tetra-nbutylammonium bromide TBAB $(0.035 \mathrm{~g}, 0.10 \mathrm{mmol})$ were combined in Dimethylformamide DMF (15 $\mathrm{mL})$. After approximately 15 - $30 \mathrm{~min}$, the alkylating agent was added, and the reaction was allowed to proceed at room temperature until a phase-transfer catalyst (TLC) indicated complete consumption of the starting material. Product could be further purified by recrystallisation (Hexane/Ethyl acetate) and yields in excess of 89 mole percent [17].

Figure 1 Chemical structure of $\mathbf{T Z}$ CDI.<smiles>CN(C)CCN1C(=O)C(=O)c2cc(Cl)ccc21</smiles>

\section{Characterization of the synthesized inhibitor: $\mathbf{T Z}_{\mathbf{C D I}}$}

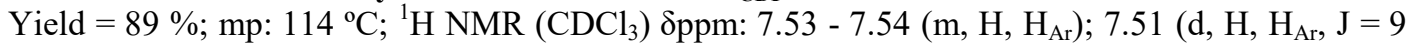
$\mathrm{Hz}) ; 6.90\left(\mathrm{~d}, \mathrm{H}, \mathrm{H}_{\mathrm{Ar}}, \mathrm{J}=9 \mathrm{~Hz}\right) ; 3.85$ (t, 2H, $\left.\mathrm{CH}_{2}, \mathrm{~J}=9 \mathrm{~Hz}\right) ; 3.75$ (t, 2H, $\left.\mathrm{CH}_{2}, \mathrm{~J}=9 \mathrm{~Hz}\right) ; 2.15(\mathrm{~m}, 6 \mathrm{H}$,

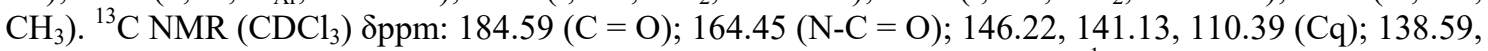
126.08, $113.36\left(\mathrm{CH}_{\mathrm{Ar}}\right) ; 55.90,46.79\left(\mathrm{CH}_{2}\right) ; 45.09\left(\mathrm{CH}_{3}\right)$. Infra Red $(\mathrm{KBr}) \mathrm{cm}^{-1}: 3565,3174,30815(\mathrm{C}-\mathrm{H})$, 2975, $1720(\mathrm{C}=\mathrm{O}), 1607(\mathrm{NC}=\mathrm{O}), 1445,1472(\mathrm{C}=\mathrm{C})$ 1185,1123 (N-C), $654(\mathrm{C}-\mathrm{Cl})$.

\section{Corrosion tests}

In this work, the gravimetric method, potentiodynamic polarization and electrochemical impedance spectroscopy, the effect of temperature, adsorption isotherm, and thermodynamic parameters were used for the investigation of the inhibition efficiency of $\mathbf{T} \mathbf{Z}_{\mathbf{C D I}}$. Then, scanning electron microscopy (SEM) was used to study the surface morphology of the mild steel before and after inhibition. All of these experimental techniques were analyzed in detail by Tribak et al. [18]. 
http://wjst.wu.ac.th

\section{Computational methods}

\section{Gaussian calculations}

Full quantum chemical calculations were carried out with the aid of Gaussian 09 and GaussView 5.0 software package programs [19], using the DFT approach, which involves Becke's 3-parameter hybrid functional and Lee-Yang-Paar's correlation functional (B3LYP) combined with the 6-31G+(d,p) basis function [20]. The purpose of this study was to investigate the interaction between the metal and the inhibitor. Some quantum chemical parameters [21,22]' such as the energy of the highest occupied molecular orbital $\left(E_{\text {НОмO }}\right)$, the energy of the lowest unoccupied molecular orbital $\left(E_{L U M O}\right)$, the ionization potential $(I P)$, electron affinity $(E A)$, the energy gap $\left(\Delta E_{\text {gap }}\right)$, total hardness $(\eta)$, and electronegativity $(\chi)$ were calculated according to the following equations with $I P=-E_{H O M O}, E A=-E_{L U M O}$, respectively;

$$
\begin{aligned}
\Delta E_{\text {gap }} & =E_{\mathrm{LUMO}}-E_{\mathrm{HOMO}} \\
& =\frac{I P-E A}{2} \\
\chi & =\frac{I P+E A}{2}
\end{aligned}
$$

\section{Fukui functions}

In this work, the evaluation of the Fukui functions [23] have been employed to analyze the local and global selectivity behavior of the molecule towards corrosion, to define the electrophilic and nucleophilic Fukui functions for a site $k$ in a molecule via Equations [24].

For nucleophilic attack

$$
f_{k}^{+}=q_{N+1}-q_{N}
$$

For electrophilic attack

$$
f_{k}^{-}=q_{N}-q_{N-1}
$$

Finally, the values of these Fukui functions were used to examine which atoms in the inhibitors were more prone to undergo electrophilic or a nucleophilic attack

\section{Results and discussion}

The studied 5-Chloroisatin derivative [25], namely $\mathbf{T} \mathbf{Z}_{\mathbf{C D I}}$, was synthesized by the $\mathrm{N}$-alkylation of 5-Cloroisatin [26-29] with Chloro-N,N-dimethylethanamine under the conditions of catalysis by phase transfer for $48 \mathrm{~h}$.<smiles>O=C1Nc2ccc(Cl)cc2C1=[OH+]</smiles>

TZ

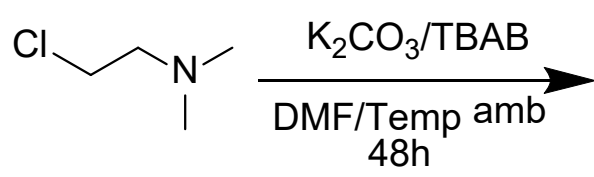
$48 \mathrm{~h}$<smiles>CN(C)CCN1C(=O)C(=O)c2cc(Cl)ccc21</smiles>

Scheme 1 Synthesis of $\mathbf{T Z}$ CDI. 


\section{Gravimetric measurements}

Table 1 summarizes the obtained results from weight loss tests, such as corrosion rate $\left(C_{R}\right)$ and inhibition efficiency $(I E \%)$, in the absence and in the presence of $\mathbf{T} \mathbf{Z}_{\mathbf{C D I}}$ at different concentrations in $1 \mathrm{M}$ $\mathrm{H}_{3} \mathrm{PO}_{4}$ solution at $303 \mathrm{~K}$ for $6 \mathrm{~h}$ of immersion on mild steel.

The corrosion rate $\left(C_{R}\right)$ and the $I E \%$ was determined by using following equation;

$$
\begin{aligned}
& C_{\mathrm{R}}=\frac{W_{\mathrm{b}}-W_{\mathrm{a}}}{A t} \\
& \mathrm{IE} \%=\left(1-\frac{w_{\mathrm{i}}}{w_{0}}\right) \times 100
\end{aligned}
$$

$W_{b}$ and $W_{a}$ are the weights of the sample before and after immersion in the test solution, $w_{0}$ and $w_{i}$ are the values of weight loss corrosion of mild steel in the absence and presence of inhibitor, $A$ the surface of the mild steel specimen $\left(\mathrm{cm}^{2}\right)$, and $t$ is the exposure time $(\mathrm{h})$.

Table 1 Corrosion rate and inhibition efficiency at different concentrations of 5-chloro-1-(2-

\begin{tabular}{|c|c|c|}
\hline $\begin{array}{c}\text { Concentration } \\
\text { (M) }\end{array}$ & $\begin{array}{c}\mathrm{C}_{\mathrm{R}} \\
\left(\mathrm{mg} \cdot \mathrm{cm}^{-2} \cdot \mathrm{hr}^{-1}\right)\end{array}$ & $\begin{array}{l}\text { IE } \\
(\%)\end{array}$ \\
\hline Blank & 0.470 & - \\
\hline $10^{-3}$ & 0.038 & 91.91 \\
\hline $5.10^{-4}$ & 0.065 & 86.21 \\
\hline $10^{-4}$ & 0.076 & 83.91 \\
\hline $5.10^{-5}$ & 0.164 & 65.16 \\
\hline $10^{-5}$ & 0.227 & 51.73 \\
\hline $10^{-6}$ & 0.237 & 49.60 \\
\hline
\end{tabular}
(dimethylamino) ethyl) indoline-2,3-dione for mild steel in $0.1 \mathrm{M} \mathrm{H}_{3} \mathrm{PO}_{4}$ ).

It is clear from Table 1 that the $I E \%$ increased and the $C_{R}$ decreased with the increase of the concentration and reached a maximum inhibition efficiency value of $91 \%$, reported at a concentration of $10^{-3} \mathrm{M}$ inhibitor $\left(\mathbf{T Z}_{\mathbf{C D I}}\right)$, which shows that the inhibitor had a good tendency for corrosion inhibition. This trend may be due to a molecular size and the presence of functional groups in its structure, which could form a protective layer on the metallic surface and therefore retard the attack of the mild steel surface by phosphoric acid; Tribak et al. confirmed this by the SEM.

\section{Effect of temperature on anticorrosion activity}

The effect of temperature on the inhibition efficiency of $\mathbf{T} \mathbf{Z}_{\mathbf{C D I}}$ for mild steel in $1 \mathrm{M} \mathrm{H}_{3} \mathrm{PO}_{4}$ solution in the absence and presence of inhibitor at temperatures ranging from 303 to $323 \mathrm{~K}$ was investigated by weight loss. The analysis of the obtained data is included in Table $\mathbf{2}$ and is presented in Figure 2 below. 
Table 2 Effect of temperature results for mild steel in $1 \mathrm{M} \mathrm{H}_{3} \mathrm{PO}_{4}$ at different concentrations of $\mathbf{T Z} \mathbf{Z}_{\mathbf{C D I}}$.

\begin{tabular}{cccc}
\hline Temperature & $\begin{array}{c}\boldsymbol{C}_{\text {inh }} \\
(\mathbf{m o l} / \mathbf{L})\end{array}$ & $\begin{array}{c}\boldsymbol{C}_{\boldsymbol{R}} \\
\left(\mathbf{m g . c m}^{-2} \cdot \mathbf{h}^{-\mathbf{1}}\right)\end{array}$ & $\begin{array}{c}\boldsymbol{I E} \\
(\boldsymbol{\%})\end{array}$ \\
\hline \multirow{3}{303}{} & Blank & 0.113 & --- \\
& $10^{-3}$ & 0.007 & 94.1 \\
& $10^{-4}$ & 0.025 & 77.7 \\
& $10^{-5}$ & 0.037 & 67.1 \\
& $10^{-6}$ & 0.054 & 52.1 \\
\hline $\mathbf{3 1 3}$ & & 0.138 & --- \\
& Blank & 0.011 & 92.0 \\
& $10^{-3}$ & 0.034 & 75.6 \\
& $10^{-4}$ & 0.055 & 60.4 \\
& $10^{-5}$ & 0.074 & 46.3 \\
\hline $\mathbf{3 2 3}$ & $10^{-6}$ & 0.386 & --- \\
& & 0.039 & 89.9 \\
& Blank & 0.150 & 61.0 \\
& $10^{-3}$ & 0.251 & 34.8 \\
& $10^{-4}$ & 0.313 & 18.8 \\
\hline
\end{tabular}

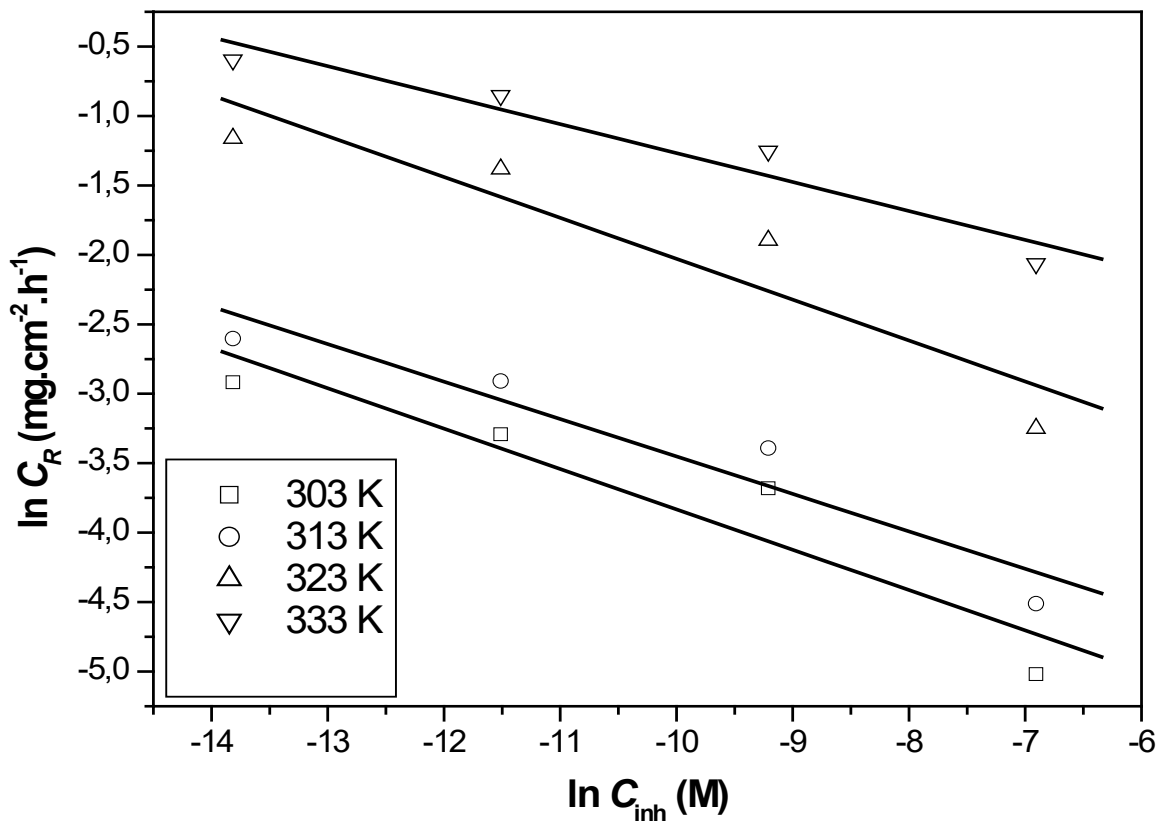

Figure 2 Change in $\mathrm{Ln} C_{\mathrm{R}}$ with $\mathrm{Ln} C_{\text {inh }}$ for mild steel in $1 \mathrm{M} \mathrm{H} \mathrm{H}_{3} \mathrm{PO}_{4}$ containing $\mathbf{T Z} \mathbf{C D I}_{\text {I }}$ at different temperatures. 
http://wjst.wu.ac.th

The rise in temperature could increase the interaction between the mild steel sheet and the corrosive medium in the absence and presence of $\mathbf{T} \mathbf{Z}_{\mathbf{C D I}}$.

As shown in Table 2, the corrosion rate increased by increasing the temperature, while the inhibition efficiency decreased by increasing the temperature. This is because the adsorption of inhibitor decreased with the rise of matrix temperature, which also indicates that the inhibitor was chemically adsorbed on the mild steel surface due to desorption initiation at elevated temperature, resulting in the lessening of $I E \%$ values of $\mathbf{T} \mathbf{Z}_{\mathbf{C D I}}$ at elevated temperatures [30].

\section{Corrosion inhibition mechanism complemented by quantum chemical study}

\section{Geometries and global reactivity}

As mentioned in the computation section, the investigated inhibitor was done by performing the DFT method using B3LYP/6-31G+ $(\mathrm{d}, \mathrm{p})$ conducive to study the adsorption of inhibitor molecules on a metallic surface by donor-acceptor interactions between the organic compound (inhibitor) and the metal [31]. The optimized molecular structures of $\mathbf{T} \mathbf{Z}_{\mathbf{C D I}}$ are shown in Figure 3.

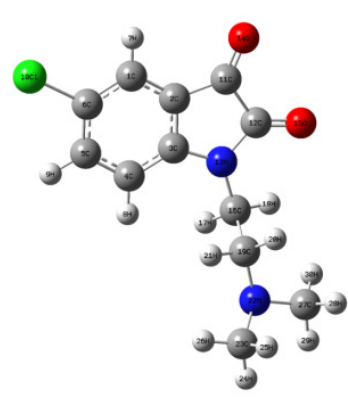

(a) ball and bond type format

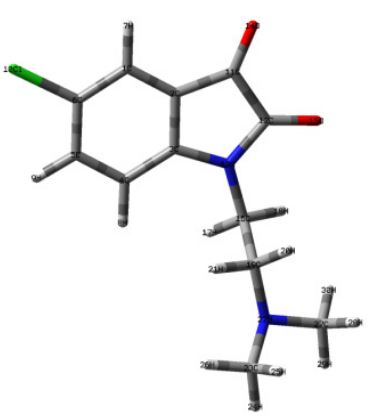

(b) tube format

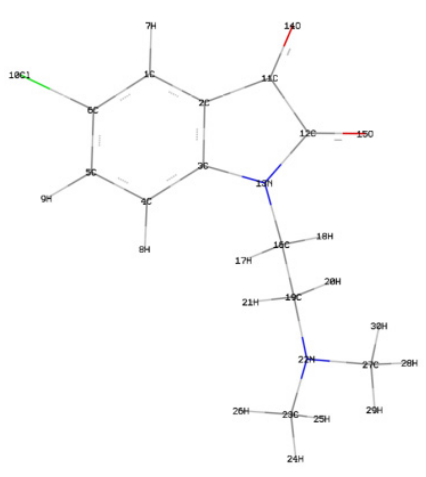

(c) wireframe format

Figure 3 Optimized molecular structure of $\mathbf{T} \mathbf{Z}_{\mathbf{C D I}}$ in different formats.

In general, the inhibition efficiency of an inhibitor is associated with its electronic structure [32], especially some calculated quantum chemical descriptors such as the $E_{\mathrm{HOMO}}$, the $E_{\mathrm{LUMO}}$, the $\Delta E_{\text {gap }}, \eta, \chi$, and Fukui function. Table 3 shows the obtained values of these parameters for the studied inhibitor.

Table 3 Energetic parameters and quantum chemical descriptors of $\mathbf{T Z} \mathbf{Z}_{\mathbf{C D I}}$.

\begin{tabular}{cc}
\hline Parameters & Compound $\left(\mathbf{T Z}_{\mathbf{C D I}}\right)$ \\
\hline$-E_{\text {HOMO }}(\mathrm{eV})$ & -6.3693 \\
$-E_{L U M O}(\mathrm{eV})$ & -3.2019 \\
$\Delta E_{\text {gap }}(\mathrm{eV})$ & 3.1673 \\
$\mu($ debye $)$ & 5.6982 \\
$I P=-E_{H O M O}$ & 6.3693 \\
$E A=-E_{L U M O}$ & 3.2019 \\
$\chi=\frac{I P+E A}{2}$ & 4.7856 \\
$\eta=\frac{I P-E A}{2}$ & 0.7918 \\
\hline
\end{tabular}


http://wjst.wu.ac.th

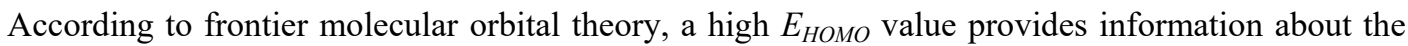
region of the inhibitor molecule from where electrons can readily be donated to the appropriate vacant orbitals of the metal that facilitates the adsorption process and, thus, is associate with better inhibition. On the other hand, $E_{L U M O}$ is connected with the affinity of the species to accept electrons [33], and a lower value of $E_{L U M O}$ implies better efficiency. The optimized molecular structures, HOMO, and LUMO of the investigated molecules are showed in Figures $\mathbf{4}$ and $\mathbf{5}$.

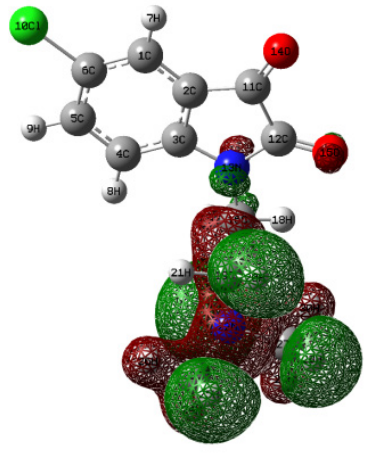

(a) Mesh format

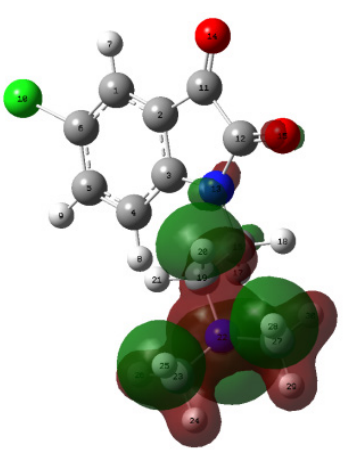

(b) Solid format

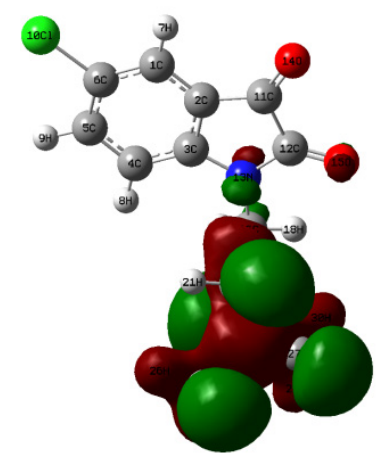

(c) Transparent format

Figure 4 Charge distribution of $\mathrm{HOMO}$ molecular orbitals in optimized $\mathbf{T Z}_{\mathbf{C D I}}$ in different formats.

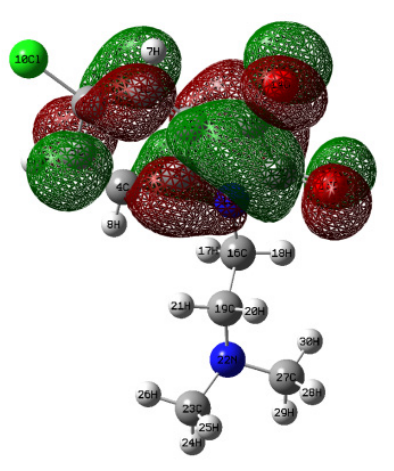

(a) Mesh format

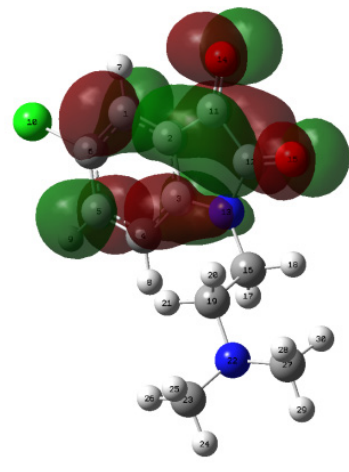

(b) Solid format

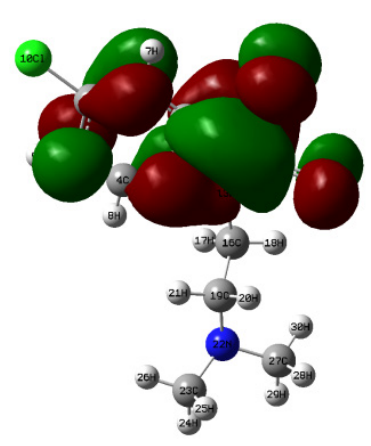

(c) Transparent format

Figure 5 Charge distribution of LUMO molecular orbitals in optimized $\mathbf{T Z}_{\mathbf{C D I}}$ in different formats.

It is noted that the HOMO orbital (Figure 4 ) of $\mathbf{T Z}$ CDI is distributed by the amide tertiary group and over the entire alkyl chain, including the $\mathrm{N}$ and $\mathrm{C}$ heteroatoms, and the hydrogen atom as well. This suggests that $\mathbf{T} \mathbf{Z}_{\mathbf{C D I}}$ can interact with metal atoms by donating charges from the electron-rich alkyl chain and amide group to the suitable vacant orbitals of the mild steel. Meanwhile, Figure 5 shows that the electron density allocation of the LUMO orbital is centralized mostly on the oxygen atoms of ketone and amide groups, and also an aromatic ring that wears the chloride atom $(\mathrm{Ar}-\mathrm{Cl})$, which indicates that $\mathbf{T} \mathbf{Z}_{\mathbf{C D I}}$ is capable of accepting charges using the electron-deficient centers around the ketone and amide groups and the aromatic ring. 
The $\Delta E_{\text {gap }}$ of a molecule represents the difference between $E_{L U M O}$ and $E_{\text {НОмO }}$ as a quantum index, It is generally acknowledged that low values of $\Delta E_{\text {gap }}$ will provide good inhibition performances, because the energy for removing an electron from the last occupied orbital will be low [34]. For the studied inhibitor, the obtained low value of $\Delta E_{\text {gap }}$ reveals the elevated inhibition efficiency of $\mathbf{T Z} \mathbf{Z}_{\mathbf{C D I}}$ by improving the reactivity of the molecule, which eases the adsorption of the investigated inhibitor on the mild steel surface.

The dipole moment is one of the most important descriptors, which is related to the polarity of the inhibitive molecule [35]. Table 7 indicates that the calculated value of the dipole moment $\left(\mu_{\text {inh }}=5.6982\right.$ Debye) for the investigated molecule is greater than that of $\mathrm{H}_{2} \mathrm{O}\left(\mu_{\mathrm{H} 2 \mathrm{O}}=1.88\right.$ Debye); this high value of $\mu$ leads to electron transfer from the $\mathbf{T} \mathbf{Z}_{\mathbf{C D I}}$ molecule to the mild steel surface. Hence, this result increases the corrosion inhibition efficiency of a molecule and shows the correlation between the dipole moment and inhibition efficiency.

A molecule with a high chemical reactivity and low kinetic stability, termed as a soft molecule, has also been reported [36], in which the global hardness and softness were determined to estimate the reactivity and stability of the inhibitive molecule. Researchers also pointed out the adsorption of inhibitor molecule onto a metallic surface occurred at the site of the molecule which had the greatest softness and lowest hardness.

From Table 3, it was observed clearly that $\mathbf{T Z}_{\mathbf{C D I}}$ has a low value of hardness and an elevated value of softness, which proves a better inhibitive performance on mild steel for the investigated 5-Chloroisatin derivative as a corrosion inhibitor.

In general terms, molecular electrostatic potential (MEP) maps can be used to determine the active canters responsible for electrophilic and nucleophilic reactions which are associated with the electronic density of a molecule [37]. Figure 6 shows the calculated MEP maps of $\mathbf{T Z} \mathbf{Z}_{\mathbf{C D I}}$. It displays red and yellow colors representing which the negative zones of the MEP are associated with electrophilic reactions, whereas the blue color represents the positive zones related to nucleophilic reactions.

Then, the studied $\mathbf{T} Z_{\mathbf{C D I}}$ has 4 potential centers $(\mathrm{O} 14, \mathrm{O} 15, \mathrm{~N} 13$, and $\mathrm{N} 22)$ effective for electrophilic reactions. Also, the aromatic ring present in the molecular structure of $\mathbf{T} \mathbf{Z}_{\mathbf{C D I}}$ is considered as being nucleophilic reactions.

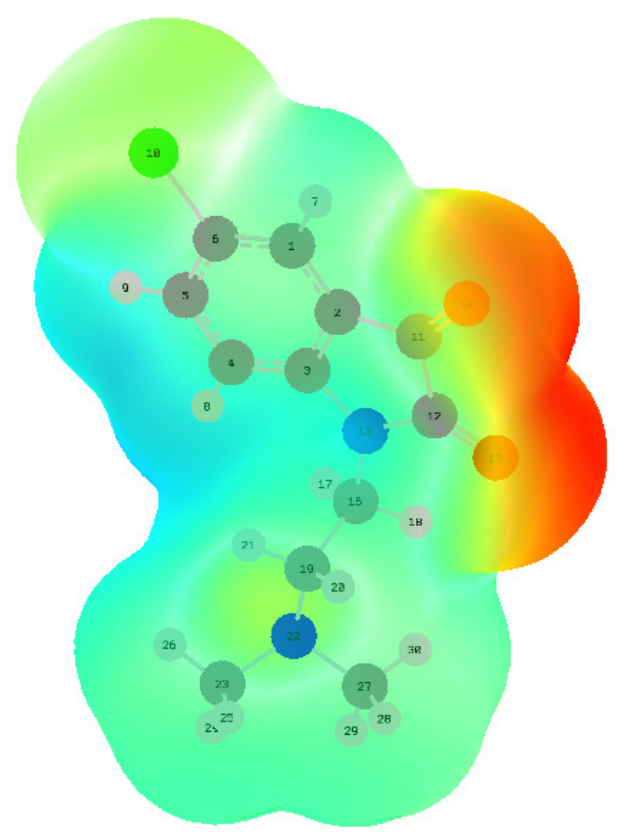

Figure 6 MEP surface of compound $\mathbf{T Z} \mathbf{C D I}_{\mathbf{C D}}$. 


\section{Local reactivity}

The Fukui theory of reactivity and selection for every atom in the inhibitor has been calculated at the B3LYP/6-31G $+(\mathrm{d}, \mathrm{p})$ level, in order to have an understanding of the local reactivity of the 5Chloroisatin derivative $\left(\mathbf{T Z}_{\mathbf{C D I}}\right)$.

Although Mulliken atomic charges do not have absolute meaning, they provide a crude but useful description of the electron-density distribution in the molecule. All the nitrogen and oxygen atoms for a molecule possess an excess of negative charge. The oxygen and nitrogen atoms are assumed to play a key role in the inhibition action because these are the most negative centers of the compound (Table 4).

Table 4 Fukui functions for $\mathbf{T} \mathbf{Z}_{\mathbf{C D I}}$ calculated using DFT.

\begin{tabular}{cccc}
\hline Atoms & $\boldsymbol{q}_{\boldsymbol{N}}$ & $\boldsymbol{f}_{\boldsymbol{k}}^{+}$ & $\boldsymbol{f}_{\boldsymbol{k}}^{-}$ \\
\hline $1 \mathrm{C}$ & 0.1209 & 0.0485 & 0.1090 \\
$2 \mathrm{C}$ & 0.0068 & 0.0217 & 0.0117 \\
$3 \mathrm{C}$ & 0.3267 & 0.0228 & 0.0073 \\
$4 \mathrm{C}$ & 0.0649 & 0.0291 & 0.0821 \\
$5 \mathrm{C}$ & 0.0656 & 0.0448 & 0.1036 \\
$6 \mathrm{C}$ & -0.2554 & 0.0337 & -0.0360 \\
$10 \mathrm{Cl}$ & 0.0856 & 0.1067 & 0.1484 \\
$11 \mathrm{C}$ & 0.2280 & 0.0292 & 0.0635 \\
$12 \mathrm{C}$ & 0.4974 & 0.0053 & 0.0545 \\
$13 \mathrm{~N}$ & -0.7101 & 0.0184 & 0.1801 \\
$14 \mathrm{O}$ & -0.3485 & 0.0525 & 0.1784 \\
$15 \mathrm{O}$ & -0.3938 & 0.0355 & 0.1372 \\
$16 \mathrm{C}$ & 0.2610 & 0.0492 & 0.0461 \\
$19 \mathrm{C}$ & 0.1788 & 0.0090 & 0.0138 \\
$22 \mathrm{~N}$ & -0.4508 & 0.0768 & 0.1476 \\
$23 \mathrm{C}$ & 0.1587 & 0.0032 & 0.0376 \\
$27 \mathrm{C}$ & 0.1639 & 0.0022 & 0.0288 \\
\hline
\end{tabular}

Generally, the preferred site for nucleophilic attack is the atom in the molecule where the value of $f_{k}^{+}$is maximum and is associated with LUMO energy, while the site for electrophilic attack is controlled by the values of $f_{k}^{-}$and is associated with HOMO energy [38].

Through comparing these Fukui indices, the results reported in Table 4, reveal that the $f_{k}^{+}$at $\mathrm{O} 14$, $\mathrm{O} 15$ and N13, N22 atoms were the highest values for a molecule, which indicated that these atoms preferred to provide electrons to form coordinate bonds with the metal atoms, so these atoms were the electrophilic reactive sites during absorption. Furthermore, the highest $f_{k}^{-}$values of inhibitor studied were $\mathrm{C} 1, \mathrm{C} 2, \mathrm{C} 3, \mathrm{C} 4, \mathrm{C} 5, \mathrm{C} 6$, and $\mathrm{O} 15$, which implied that these atoms favored acceptance of electrons from metal atoms to form back-donating.

Interestingly, $\mathrm{O} 15$ atom had dual characteristics of both donating and back-donating electrons. We hold that this diminished its adsorption capacity, since the donating process was a more important factor in evaluating local reactivity for a corrosion inhibitor $\left(\mathbf{T Z}_{\mathbf{C D I}}\right)$. 


\section{Conclusions}

The present study revealed that $\mathbf{T} \mathbf{Z}_{\mathbf{C D I}}$ is an excellent inhibitor for the corrosion of mild steel in solution of phosphoric acid. The highest valuable result for corrosion inhibition performance of $91 \%$ was achieved with concentration of $10^{-3} \mathrm{M}$ at $303 \mathrm{~K}$. Molecular modeling was used to evaluate the structural, electronic, and reactivity parameters of $\mathbf{T Z}_{\mathbf{C D I}}$ in relation to its effectiveness as a corrosion inhibitor by means of DFT, the B3LYP/6-31G method. The results showed that the quantum chemical descriptors perfectly described the inhibitory activity of $\mathbf{T} \mathbf{Z}_{\mathbf{C D I}}$. Hence, its excellent inhibition properties are due to the presence of functional groups appearing in the molecular structures of the inhibitor. The results obtained from the computational study back up the experimentally obtained results.

\section{Acknowledgements}

The authors would like to thank all the people who helped to carry out this work, such as ${ }^{1} \mathrm{H}$ NMR, ${ }^{13} \mathrm{C}$ NMR, and anticorrosion activity.

\section{References}

[1] T Liu, Z Guo, Z Zeng, N Guo, Y Lei, T Liu, S Sun, X Chang, Y Yin and X Wang. Marine bacteria provide lasting anticorrosion activity for steel via biofilm-induced mineralization. ACS Appl. Mater. Interfaces 2018; 10, 40317-27.

[2] Z Tribak, MK Skalli and O Senhaji. Anticorrosion activity for some 5-Chloroisatin derivatives. Éditions Universitaires Européennes. German, 2017, p. 1-46.

[3] K Babić-Samardžija, KF Khaled and N Hackerman. N-heterocyclic amines and derivatives as corrosion inhibitors for iron in perchloric acid. Anti Corros. Method. Mater. 2005; 52, 11-21.

[4] Z Tribak, YK Rodi, H Elmsellem, I Abdel-Rahman, A Haoudi, MK Skalli, Y Kadmi, B Hammouti, MA Shariati and EM Essassi. 5-chloro-1-octylindoline-2,3-dione as a new corrosion inhibitor for mild steel in hydrochloric acid solution. J. Mater. Environ. Sci. 2017; 8, 1116-27.

[5] Z Tribak, Y Kharbach, A Haoudi, MK Skalli, YK Rodi, ME Azzouzi, A Aouniti, B Hammouti and O Senhaji. Study of new 5-chloro-isatin derivatives as efficient organic inhibitors of corrosion in 1M HCl medium: Electrochemical and SEM studies. J. Mater. Environ. Sci. 2016; 7, 2006-20.

[6] SK Bhati and A Kumar. Synthesis of new substituted azetidinoyl and thiazolidinoyl-1,3,4thiadiazino (6,5-b) indoles as promising anti-inflammatory agents. Eur. J. Med. Chem. 2008; 43 2323-30.

[7] Y Zhou, J Liu, M Zheng, S Zheng, C Jiang, X Zhou, D Zhang, J Zhao, D Ye, M Zheng, H Jiang, D Liu, J Cheng and H Liu. Structural optimization and biological evaluation of 1,5-disubstituted pyrazole-3-carboxamines as potent inhibitors of human 5-lipoxygenase. Acta Pharm. Sin. B 2016; 6 $32-45$.

[8] K Bettayeb, OM Tirado, S Marionneau-Lambot, Y Ferandin, O Lozach, JC Morris, S MateoLozano, P Drueckes, C Schächtele, MHG Kubbutat, F Liger, B Marquet, B Joseph, A Echalier, JA Endicott, V Notario and L Meijer. Meriolins, a new class of cell death-inducing kinase inhibitors with enhanced selectivity for cyclin-dependent kinases. Cancer Res. 2007; 67, 8325-34.

[9] Z Tribak, OE Amin, MK Skalli, O Senhaji, YK Rodi and M Iraqui. N-alkylation methods, characterization and evaluation of antibacterial activity of some novel 5-chloroisatin derivatives. Int. J. Eng. Res. Appl. 2017; 7, 21-4.

[10] Z Tribak, OE Amin, MK Skalli, O Senhaji, YK Rodi and MH Iraqui. Synthesis, characterization, and antibacterial activity of some novel 5-chloroisatin derivatives. Int. J. Eng. Res. Appl. 2017; 7, 66-70.

[11] Z Tribak, MK Skalli, A Haoudi, YK Rodi, O Senhaji and EM Essassi. Cyclocondensation, characterization and antibacterial activities of novel 5-chloro-1HIndole-2,3-dione derivatives. $J$. Appl. Microbiol. Biochem. 2018; 2, 1-4. 
http://wjst.wu.ac.th

[12] Z Tribak, A Chda, MK Skalli, A Haoudi, YK Rodi, O Senhaji, EM Essassi, R Bencheikh and KE Abida. Theoretical approach using DFT and muscle relaxant effects of 5-chloroisatin derivatives. Int. J. Chem. Technol. 2018; 2, 105-15.

[13] ER El-Sawy, AH Mandour, SM El-Hallouty, KH Shaker and HM Abo-Salem. Synthesis, antimicrobial and anticancer activities of some new N-methylsulphonyl and N-benzenesulphonyl-3indolyl heterocycles: $1^{\text {st }}$ Cancer Update. Arab. J. Chem. 2013; 6, 67-78.

[14] Z Tribak, R Ghibate, MK Shalli, YK Rodi and O Senhaji. Experimental and theoretical study for corrosion inhibition in $1 \mathrm{M} \mathrm{HCl}$ solution by new 5-chloroisatin derivative. Int. J. sci. Technol. Eng. 2016; 3, 257-62.

[15] Z Tribak, MK Skalli, A Haoudi, YK Rodi and O Senhaji. DFT, quantum chemical study and biological effects of a heterocyclic molecular. J. Biotech. Biores. 2019; 1, 1-5.

[16] Z Tribak, MK Skalli, A Haoudi, YK Rodi and O Senhaji. Experimental approach, computational DFT investigation and a biological activity in the study of an organic heterocyclic compound. Arc. Org. Inorg. Chem. Sci. 2019; 4, 458-64.

[17] Z Tribak, A Haoudi, YK Rodi, H Elmsellem, MK Skalli, Y Ouzidan, A Mazzah and EM Essassi. Synthesis and reactivity of new heterocyclic systems derived from 5-chloro-1H-indole-2,3-dione. Moroccan J. Chem. 2016; 4, 1157-63.

[18] Z Tribak, A Haoudi, MK Skalli, KY Rodi, ME Azzouzi, A Aouniti, B Hammouti and O Senhaji. 5Chloro-1H-indole-2,3-dione derivative as corrosion inhibitor for mild steel in $1 \mathrm{M}$ $\mathrm{H}<\mathrm{inf}>3</$ inf $>\mathrm{PO}<$ inf $>4</$ inf $>$ : Weight loss, electrochemical and SEM studies. J. Mater. Environ. Sci. 2017; 8, 299-309.

[19] M Frisch, GW Trucks, HB Schlegel, GE Scuseria, MA Robb, JR Cheeseman, G Scalmani, V Barone and B Mennucci. Ga Petersson, Gaussian 09, revision a. 02, gaussian, Wallingford, CT. 200, 2009.

[20] J Poater, M Duran and Miquel Solà. Parametrization of the Becke3-LYP hybrid functional for a series of small molecules using quantum molecular similarity techniques. J. Comput. Chem. 2001; 22, 1666-78.

[21] Z Tribak, MK Skalli, O Senhaji and YK Rodi. Experimental and theoretical DFT study on synthesis of novel 5-chloroisatin derivatives via 1,3-dipolar cycloaddition reactions between allyl-5chloroindoline-2,3-dione and 4-chlorobenzaldoxime. Int. J. Appl. Chem. 2017; 4, 1-6.

[22] Z Tribak, MK Skalli, O Senhaji and YK Rodi. Synthesis, structural characterization and comparison of experimental and theoretical results by DFT level of molecular structures of 1,2,3-triazoles derived from 5-chloroisatin. Int. J. Adv. Chem. 2017; 5, 91-5.

[23] T Fievez, N Sablon, FD Proft, PW Ayers and P Geerlings. Calculation of Fukui functions without differentiating to the Number of electrons. 3. local Fukui function and dual descriptor. J. Chem. Theor. Comput. 2008; 1, 1065-72.

[24] A Dwivedi, V Baboo and A Bajpai. Fukui function analysis and optical, electronic, and vibrational properties of tetrahydrofuran and its derivatives: A complete quantum chemical study. $J$. Theor. Chem. 2015; 2015, 1-11.

[25] Z Tribak, MK Skalli, O Senhaji, YK Rodi, A Haoudi and EM Essassi. A Review on recent advances and applications of 5-chloroisatin and its derivatives in design and synthesis of new organic compounds. Am. Int. J. Res. Formal Appl. Nat. Sci. 2017; 19, 41-50.

[26] Z Tribak, YK Rodi, A Haoudi, EM Essassi, F Capet and H Zouihri. 5-chloro-1-methylindoline-2, 3dione. IUCrData 2016; 1, 1-3.

[27] Z Tribak, YK Rodi, A Haoudi, EM Essassi, F Capet and H Zouihri. 1-allyl-5-chloroindoline-2, 3dione. IUCrData 2016; 1, 1-2.

[28] Z Tribak, YK Rodi, A Haoudi, EM Essassi, F Capet and H Zouihri. 1-(12-Bromododecyl)-5chloroindoline-2,3-dione. IUCrData 2016; 1, 1-2.

[29] Z Tribak, YK Rodi, A Haoudi, EM Essassi, F Capet and H Zouihri. 1-Benzyl-5-chloroindoline-2, 3dione. IUCrData 2016; 1, 1-2.

[30] V Sivakumar, K Velumani and S Rameshkumar. Colocid dye - a potential corrosion inhibitor for the corrosion of mild steel in acid media. Mater. Res. 2018; 21, 1-10. 
http://wjst.wu.ac.th

[31] Z Tribak, YK Rodi, H Elmsellem, A Haoudi, MK Skalli, Y Ouzidan, O Senhaji, NK Sebbar, EM Essassi and B Hammouti. The role of 1-allyl-5-chloro-indoline-2,3-dione on the corrosion inhibition of steel in HCL media. J. Mar. Chim. Heterocycl. 2017; 16, 157-65.

[32] MO Abdulazeez, AK Oyebamiji and B Semire. DFT and QSAR study of corrosion inhibition on 3, 5-di-substituted pyrazole derivatives with heteroatom on position one. Leban. Sci. J. 2016; 17, 217 32.

[33] L Guo, S Kaya, IB Obot, X Zheng and Y Qiang. Toward understanding the anticorrosive mechanism of some thiourea derivatives for carbon steel corrosion: A combined DFT and molecular dynamics investigation. J. Colloid Interface Sci. 2017; 15, 478-85.

[34] GM Al-Mazaideh, TS Ababneh, KH Abu-Shandi, RMAQ Jamhour, HJA Salman, AM Al-Msiedeen and SM Khalil. DFT calculations of Mesembryanthemum nodiflorum compounds as corrosion inhibitors of aluminum. Phys. Sci. Int. J. 2016; 12, 1-7.

[35] J Bhawsar, PK Jain, P Jain and MR Bhawsar. Computational study of corrosion potential of Ciprofloxacin drug: DFT approach. Asian J. Res. Chem. 2014; 7, 386-9.

[36] EE Elemike, DC Onwudiwe, HU Nwankwo and EC Hosten. Synthesis, crystal structure, electrochemical and anti-corrosion studies of Schiff base derived from o-toluidine and ochlorobenzaldehyde. J. Mol. Struct. 2017; 1136, 253-62.

[37] S Gosav, N Paduraru, D Maftei, ML Birsa and M Praisler. Quantum chemical study of a derivative of 3-substituted dithiocarbamic flavanone, Spectrochim. Acta A Mol. Biomol. Spectrosc. 2017; 172, $115-25$.

[38] B Gómez, NV Likhanova, MA Domínguez-Aguilar, R Martínez-Palou, A Vela and L Ga. Quantum chemical study of the inhibitive properties of 2-pyridyl-azoles. J. Phys. Chem. B 2006; 110, 892834. 